\title{
El derecho a la educación como fundamento de la democracia $y$ premisa para el libre desarrollo de la personalidad. ${ }^{*}$
}

\author{
The right to education as a democratic \\ pillar and as a premise for the free \\ development of personality
}

\section{Ciro Milione}

\section{Prof. Titular de Derecho Constitucional}

Facultad de Derecho y Ciencias Económicas y Empresariales

Departamento de Derecho Público y Económico

\section{Universidad de Córdoba}

E-mail: ciromilione@uco.es

\footnotetext{
* El presente artículo amplía y profundiza el análisis de algunos conceptos, nociones e ideas que constituyeron objeto de una comunicación presentada en el XVIII Congreso de la Asociación de Constitucionalistas de España "Educación y Libertades en la democracia constitucional" celebrado, en formato virtual, los días 11 y 12 de marzo de 2021. Asimismo, las conclusiones de este estudio fueron expuestas en la ponencia invitada "Reflexiones en torno al concepto de educación desde una perspectiva teleológica y jurídica" presentada en el IV Congreso Internacional "Derecho a la educación: innovación docente y mejora educativa", organizado por la Universidad de Valencia y por la Universidad de Córdoba y celebrado durante los días 4 y 5 de marzo de 2021. Por otra parte, este mismo trabajo se enmarca en el ámbito del proyecto I+D "Desafíos del Proceso de Construcción de un Espacio Europeo de Derechos Fundamentales" (DER-2017-83779-P, financiado por el Ministerio de Economía y Competitividad) dirigido por la Prof. a A. M. Carmona Contreras, de la Universidad de Sevilla.

Quisiera agradecer las aportaciones a este artículo realizadas por el Prof. Miguel Agudo Zamora, Catedrático de Derecho Constitucional, y por el Prof. José Luis Álvarez Castillo, Catedrático de Teoría e Historia de la Educación, ambos de la Universidad de Córdoba, así como su amable e inestimable labor de revisión crítica. No obstante, cualquier error, omisión o imprecisión es exclusivamente mía.

Por último, quisiera dedicar este artículo a Giulia y a Matteo por haberlo inspirado cuando un día, camino de su colegio, me preguntaron: “'papá, perchè andiamo a scuola?”.
} 
Resumen: El presente artículo se centra en el análisis de la noción de educación desde un punto de vista jurídico y filosófico. La intención del autor es demostrar que el hecho educativo representa uno de los factores más decisivos para lograr, en nuestros sistemas constitucionales, unos objetivos complejos e insoslayables que se desarrollan sobre dos planos distintos e interconectados: uno de carácter individual (el desarrollo integral de la persona), otro de carácter colectivo (la construcción de una ciudadanía crítica y, por ende, de un sistema democrático efectivo). Tras reflexionar sobre algunas de las aportaciones doctrinales (Jaeger, Freire, Galimberti etc.) e institucionales (ONU, UNESCO, jurisprudencia del Tribunal Constitucional español, etc.) más relevantes sobre el tema en cuestión, el autor analiza el derecho a la educación desde la perspectiva de su configuración jurídica como derecho social fundamental y como componente irrenunciable del derecho a un mínimo vital. Eso le brinda la oportunidad de recordar que, en materia de derechos humanos, la tradicional contraposición y jerarquización entre derechos civiles y políticos y derechos sociales, culturales y económicos no tiene razón de existir.

Palabras clave: Educación, derecho, democracia, ciudadanía, dignidad, Constitución, persona.

\begin{abstract}
This article focuses on the analysis of the notion of education from a legal and philosophical point of view. The author intends to demonstrate that, in our constitutional systems, education represents one of the most decisive factors in achieving complex and unavoidable goals: one of an individual nature (the integral development of the human person), the other of a collective nature (the construction of critical citizenship and, therefore, of an effective democratic system). After reflecting on the contributions on this subject made by some of the most relevant scholars (Jaeger, Freire, Galimberti, etc.) and institutions (UN, UNESCO, the jurisprudence of the Spanish Constitutional Court, etc.), the author analyzes the right to education from the perspective of its legal configuration as a fundamental social right and as an inalienable component of the right to a vital minimum. This allows him to recall that, in the field of human rights, the traditional contrast and hierarchy between civil and political rights and social, cultural, and economic rights has no reason to exist.
\end{abstract}


Keywords: Education, right, democracy, citizenship, dignity, Constitution, person.

Sumario: 1. Consideraciones preliminares. 2. Una primera -e insatisfactoria- aproximación al significado de la palabra educar. 3. Hacia una definición alternativa -y, posiblemente, más satisfactoria- del término educar. 4. La noción de educación desde la perspectiva de quién educa. 5. La educación como derecho social fundamental y mínimo vital. 6. Conclusiones.

"No existe educación sin sociedad humana y no existe hombre fuera de ella."

(FREIRE, P., La educación como práctica de la libertad, 1976)

"El que no puede vivir en comunidad [...] No es miembro de la ciudad, sino una bestia o un dios." (ARISTÓTELES, Política, Libro I, 1253a 14, 350 a. C.)

\section{Consideraciones preliminares}

En el momento de redactar estas líneas, el que lo hace sigue soportando, como el resto de la población española, las numerosas, y a veces confusas, medidas que las autoridades competentes han impuesto para reducir el riesgo de contagio por Covid-19 desde el pasado marzo del año 2020. Esta pandemia que tan gravemente está afectando nuestras vidas, por su propia naturaleza y características nos ha devuelto una imagen de la humanidad más semejante a la realidad concreta de nuestra existencia. Nos ha enseñado que las fronteras físicas o jurídicas que nos separan y que contribuyen a certificar nuestras diferencias -e incluso la indiferencia que de ellas deriva- se desvanecen cuando la amenaza que nos acecha no puede ser contenida por esos mismos lindes llamados a protegernos de lo ajeno (OBAMA, 2020: 11 y 12).

Los instrumentos más ortodoxos que hemos implementados, desde siglos, para proteger nuestras sociedades -obstáculos físicos o naturales, ejércitos, armas, etc.- en esta ocasión de poco han servido para contener un peligro invisible y sutil.

En la actualidad más reciente, los estudios sobre posibles vacunas parecen estar dando sus primeros frutos, mientras la comunidad científica internacional sigue investigando soluciones médicas que sean más eficaces y capaces de llegar a segmentos mayores de 
nuestros conjuntos sociales. Sin embargo, incluso ahora, como en las fases más incipientes de la pandemia, lo que contribuye más a la inflexión de las curvas de infectados y fallecidos consiste en la actuación de la ciudadanía, en su conciencia cívica y en su disposición hacia algo tan obvio -y, sin embargo, tan necesario- como el respeto debido a las normas jurídicas, a esas reglas que sacrifican y restringen nuestra libertad común para lograr un bien que se estima superior: la contención del contagio.

Como docente de Derecho Constitucional y persona que experimenta a diario, por su propia profesión, el privilegio de dirigirse a estudiantes que apenas han terminado su recorrido formativo obligatorio en el sistema español de escolarización, constato con profundo interés, a través de debates en el aula, cuáles son las razones por las que mis estudiantes entienden que el ordenamiento jurídico es capaz, en principio, de imponerse al criterio de un único individuo (MARTÍN ARMENGOL, 2013: 59-78).

Un buen número de alumnos simplemente contesta que la razón principal por la que la norma jurídica es capaz de tanto poder reside en el temor a las repercusiones jurídicas que su incumplimiento acarrearía. Una amplia mayoría, sin embargo, responde que es su carácter democrático el supuesto que las dotaría de coactividad, una característica que derivaría de la maduración, íntimamente consciente en cada uno de nosotros, de la necesidad de respetar esas reglas comunes. Pues, es ese respeto la condición básica y el presupuesto fundamental para lograr el objetivo de una convivencia pacífica, volcada en la búsqueda del bienestar común y del progreso social (KELSEN, 1979 y 1934).

Así, es legítimo preguntarse ¿cómo se realiza ese proceso de maduración? ¿De dónde viene esa conciencia compartida? ¿En qué momento un individuo deja de ser exclusivamente una unidad aislada y ajena al contexto en el que vive, para adquirir su propio rol en ese espacio común llamado ciudadanía?

Creo firmemente que la respuesta a estos interrogantes reside en la noción de paideia, de educación como instrumento integral de formación de la persona y del ciudadano, es decir, de aquel sujeto llamado a vivir bajo un conjunto de normas democráticamente establecidas -el ordenamiento jurídico- que, por definición, no puede descansar únicamente en la fuerza 
coercitiva -en ese legítimo monopolio de la violencia, por citar un concepto weberiano-. Como procuraré explicar más adelante, la educación representa un concepto con una profunda trascendencia política y jurídica y con una innegable proyección moral. Eso se debe a que la noción de educación constituye ese principio de toda ciudadanía dispuesta a mirar a la realidad que la rodea con participación, interés y espíritu crítico, animada por el deseo irrenunciable de lograr esa utopía que se halla a la base de nuestros pactos de convivencia, es decir, la "dignidad humana".

Por todo ello, ese sistema de valores y principios que llamamos Constitución, y esa misma estructura que se eleva a través de ella -el Estado constitucional-, en ausencia de un sistema educativo inspirado en esos mismos valores y principios, no perduraría más que el tiempo de una generación, pues "freedom is never more than one generation away from extinction", como afirmaba un conocido exponente del partido republicano de los Estados Unidos de América.

Así, merece la pena recordar que el conjunto de valores colectivos que hacen posible la convivencia, la paz, el desarrollo y el progreso, así como la exhortación dirigida al individuo a desarrollar su personalidad y a "ser lo que puede ser", todos ellos realmente ven su comienzo en los pupitres de un colegio.

Por todas estas razones, este trabajo pretende acercarse al concepto de educación, una de esas nociones que "resultan tan decisivas, necesarias y críticas” (MILIONE, 2020: 244) para el mundo en el que vivimos, y con el que todas y todos nos medimos a diario, no solo como docentes, sino por el mero hecho de ser $\zeta \tilde{\omega} \alpha \pi o \lambda \imath \tau \imath \kappa \alpha ́$, unos “animales políticos".

La primera parte de este trabajo va a consistir en una aproximación ${ }^{1}$ al concepto de educación. Lo haré sin adentrarme, de inmediato, en el terreno dogmático de los derechos humanos, un terreno en el que dicho concepto ha sido ampliamente tratado como demuestra, del resto, la copiosa jurisprudencia de Tribunales nacionales y supranacionales y numerosos trabajos doctrinales.

${ }^{1}$ Utilizar otro sustantivo más ambicioso no haría justicia de la complejidad del término que quiere formar objeto de este estudio. 
Aunque corra el riesgo de adelantar algunos temas que trataré más detenidamente a continuación, en esta sede considero oportuno realizar una aclaración de tipo preliminar. Siendo consciente de la complejidad y de la amplitud de todo lo que rodea la noción de educación, en este estudio me centraré en lo que entraña este término desde su significado más auténtico. Así, omitiré el análisis de otros aspectos que, por ejemplo, nuestro texto constitucional reconecta a esa misma noción: la libertad de enseñanza, el derecho a recibir formación religiosa, la creación de centros docentes, la autonomía universitaria, etc. En otras palabras, me interesa reflexionar sobre el sentido jurídico y político de la palabra educación a partir de los propósitos esenciales que esta actividad humana persigue y que solo en parte coinciden con esa definición que TOMAS y VALIENTE (1981) nos ofreció hace ya 40 años: "la comunicación de unas convicciones morales, filosóficas y religiosas conformes con una determinada ideología”.

También es cierto que, para conseguir este objetivo no será posible ejecutar una revisión bibliográfica completa de los trabajos y estudios que han tenido su foco sobre el concepto objeto de mi análisis. La razón es obvia: eso supondría embarcarse en una aventura materialmente imposible, desproporcionada para el tipo de trabajo que me dispongo a realizar. Simplemente, concentraré mi atención en la opinión de algunos autores que, en el pasado y en la actualidad, han tratado la cuestión educativa desde el prisma político y jurídico, preocupándose de darle un significado coherente, además de esa trascendencia individual y colectiva a la que aludía anteriormente.

Qué duda cabe de que no estarán todos y todas los que deberían estar. La selección de esos autores ha sido personal y me dispongo desde ya a asumir, con la necesaria humildad, cualquier crítica honesta.

Por otra parte, me detendré sobre uno de los documentos que con más atención se han ocupado de describir los objetivos que la educación debería perseguir como instrumento de desarrollo social e individual. Se trata de un estudio redactado en el año 1996, por la UNESCO, ("La Educación encierra un tesoro, informe a la UNESCO de la Comisión Internacional sobre la Educación para el Siglo XXI"), cuya actualidad, por ciertos aspectos, sigue siendo incontestable. 
La segunda y última parte de este trabajo se centrará, sin embargo, sobre la configuración de la educación como derecho social fundamental y como componente irrenunciable del derecho a un mínimo vital. Eso me brindará la oportunidad de recordar que, cuando hablamos de derechos humanos, esa conocida contraposición y jerarquización entre derechos civiles y políticos y derechos sociales, culturales y económicos no debería tener razón de existir.

\section{Una primera -e insatisfactoria- aproximación al significado de la palabra educar}

El primer paso que se suele dar para conocer el significado de un concepto dudoso consiste en acudir a un diccionario, posiblemente al que consideremos más digno de confianza.

Es realmente significativa la definición que la Real Academia Española (2020) da del verbo educar. La descripción que se halla en el Diccionario de esa prestigiosa institución se articula en cinco puntos distintos que procuran ofrecer las acepciones más comunes que se atribuyen al lema objeto de este estudio. Es de entender que la primera de esas acepciones es la más frecuente o la más útil para acotar el significado del término principal y que la última viene a ser la menos adecuada para esos mismos fines.

Pues bien, es relevante que la primera definición de la palabra educar es la que la describe como un verbo transitivo que supone "dirigir, encaminar, doctrinar". Esa acción es delineada más ampliamente en el segundo punto en el que se aclara que educar supone "desarrollar o perfeccionar las facultades intelectuales y morales [...] por medio de preceptos, ejercicios, ejemplos, etc.”. En ese mismo punto, el Diccionario indica los sujetos destinatarios de la acción educativa: esos son, básicamente, el "niño" y el "joven”. La tercera definición, desplaza en foco de atención a la dimensión corporal del hecho de educar. A tal propósito, el Diccionario matiza que tal acción puede consistir también en “desarrollar las fuerzas físicas por medio del ejercicio, haciéndolas más aptas para su fin". Por último, la cuarta y quinta acepción hacen referencia, respectivamente, al perfeccionamiento y al afinamiento de los sentidos (“educar el gusto, el oído") y al enseñamiento "de los buenos usos de urbanidad y cortesía". 
Sacando algunas conclusiones preliminares de esta definición ofrecida por la Real Academia Española, deberíamos entender que educar entraña un principio de superioridad o jerarquía entre el que "dirige, encamina o indoctrina" y el que es "dirigido, encaminado o adoctrinado"; que este último sujeto es "un niño" o "un joven", lo que supondría, por lo tanto, que educar es algo que compete a los adultos y ser educado, sin embargo, algo que atañe a las generaciones más jóvenes; que educar implica ofrecer "preceptos" y "ejemplos" y, además, requiere la realización de actividades en forma de "ejercicios". Por último, esa definición supone que la educación tiene, por lo menos dos dimensiones diversas: una intelectual que atañe a facultades de índole moral que hacen posible la convivencia (los "buenos usos de urbanidad y cortesía") o el desarrollo de aspectos de la personalidad (“educar el gusto, el oído, etc.”); y una corpórea, que consistiría en la mejora de unas prestaciones físicas a través del ejercicio.

Si educar es básicamente eso, he de admitir que no puedo considerarme del todo satisfecho.

\section{Hacia una definición alternativa $-y$, posiblemente, más satisfactoria- del término educar}

Para comenzar a profundizar mi análisis, considero oportuno volver mi mirada atrás en el tiempo, a esa sociedad -la Grecia clásica- que no solo contribuyó de forma decisiva al desarrollo de la cultura y del pensamiento occidental, sino que, particularmente, se preocupó de fundar esa ciencia práctica a la base del concepto objeto de este estudio: la pedagogía.

Como es sabido, en la Grecia clásica se definía con el concepto de $\pi \alpha \imath \delta \varepsilon i ́ \alpha$ el modelo educativo dirigido a los jóvenes, en vigor en Atenas entre los siglos VI y IV a.C. Ese modelo se articulaba en dos vertientes distintas: una "física", que pretendía enseñar la cura y el fortalecimiento del cuerpo, y otra "espiritual", que buscaba favorecer la integración de los jóvenes individuos en el contexto social de la $\pi o ́ \lambda l \varsigma$, educándoles en aquellos valores y principios fundamentales (cuyo conjunto se definía है $\theta o \varsigma$ ) en los que se reconocía la comunidad política. 
El conocido filólogo alemán W. W. JAEGER dedicó una parte importante de su trayectoria académica y científica al análisis del modelo educativo de la Grecia clásica. En su obra principal afirmaba que "todo pueblo que alcanza un cierto grado de desarrollo se halla naturalmente inclinado a practicar la educación", pues en ello consiste "el principio mediante el cual la comunidad humana conserva y transmite su peculiaridad física y espiritual". Así, para ese autor, mientras la supervivencia de la especie, en su corporeidad y materialidad, se garantiza por medio de la procreación; la educación constituye una de las formas a través de las que se asegura la supervivencia de nuestro patrimonio de valores y de creencias, en su dimensión social o espiritual.

En este sentido, para JAEGER (2001: 3) "en la educación actúa la misma fuerza vital, creadora y plástica, que impulsa espontáneamente a toda especie viva al mantenimiento y propagación de su tipo".

Educar, entonces, significa en primer lugar transmitir.

El problema que se pone a este respecto, sin embargo, es el que atañe al mensaje que es objeto de esta transmisión y, más concretamente, a su carácter de estabilidad, permanencia o inmutabilidad. La educación, en efecto, en su esencia más genuina, no puede consistir, exclusivamente, en la mera transmisión de dogmas incuestionables que se repiten de boca en boca y de generación en generación. En este sentido, cabría recordar esa frase célebre, cuya autoría se atribuye a José Ortega y Gasset, que afirma "Siempre que enseñes, enseña a la vez a dudar de lo que enseñas".

Por esa misma razón, JAEGER nos advierte que:

\footnotetext{
"A la estabilidad de las normas válidas corresponde la solidez de los fundamentos de la educación. De la disolución y la destrucción de las normas [y de los valores sobre los que esas mismas descansan] resulta la debilidad, la falta de seguridad y aun la imposibilidad absoluta de toda acción educadora. Esto ocurre cuando la tradición es violentamente destruida o sufre una íntima decadencia." (ibídem: 4)
} 
Aunque el mismo autor se preocupa de precisar, inmediatamente después de esas palabras, que la inmutada permanencia de esos valores y normas no es necesariamente un signo inequívoco de seguridad.

En efecto, la educación bebe de esa doctrina del obrar humano que llamamos moral, se nutre de sus valores, pero la educación misma es premisa de un verdadero progreso solo si la transmisión de esos valores se hace en un sentido crítico y analítico. Educar en valores, enseñarlos, supone además cuestionarlos, bien para reiterar su necesidad y afianzar su existencia; bien para medir su capacidad de resistencia al paso del tiempo, a la evolución del sentir social y determinar, cuando su obsolescencia resulte evidente, su entrega a las páginas de nuestro pasado colectivo.

Así, si es cierto que educar significa transmitir, el objeto de esta transmisión no es neutral. Debe suponer en quién educa y, a la postre en quién es educado, la capacidad de pensar críticamente, de cuestionar la realidad a la luz del presente y del pasado, de investigar las causas últimas de los fracasos y de los éxitos de nuestros modelos sociales.

Educar significa pues preocuparse, en el sentido etimológico del término: "ocuparse de algo antes de que eso ocurra", "prevenir", desarrollar esa capacidad que consiste en la búsqueda de soluciones y remedios a situaciones críticas o relevantes que puedan darse en un futuro.

En un cierto sentido, el educador debería “educar a la preocupación”. Para explicar esta idea que puede parecer confusa, es útil acudir a la construcción etimológica de otro término que -como es sabido- se caracteriza por su fuerte connotación despreciativa: la palabra idiota. Es TUCÍDIDES (s.f.) que nos ofrece el significado original de esa expresión en una de sus obras más conocidas: la Guerra del Peloponeso. En particular, interpretando conjuntamente el párrafo 48 del Libro II y el párrafo 10 de libro III es posible afirmar que con la palabra $i \delta \imath \omega ́ \tau \eta \varsigma$ se indicaba el "individuo", el "particular" que vivía de espaldas a los asuntos públicos, preocupado solo de sus intereses privados, indiferente a la política, del todo ajeno a la formación de la voluntad común en ese nuevo régimen político llamado entonces "democracia” y, por ende, un "hombre inútil y sin provecho" $(40, \mathrm{II})$. 
Estas mismas ideas conducían FREIRE a afirmar en una entrevista pública para el diario El País que:

"la educación es siempre un quehacer político. No hay, pues, una dimensión política de la educación, sino que ésta es un acto político en sí misma. El educador es un político y un artista; lo que no puede ser es un técnico frío. Ello significa que tiene que tener una cierta opción: la educación para qué, la educación en favor de quiénes, la educación contra qué.” (MARIN, 1978).

En otro contexto, el mismo pedagogo y filósofo brasileño reflexionaba en torno a la democracia como forma de vida antes que política, una forma que presupone una "gran dosis de transitividad de conciencia en el comportamiento humano", algo que es posible lograr a través de la educación que permite que "el hombre se lance al debate, al examen de sus problemas y de los problemas comunes, [...] que el hombre participe" (FREIRE, 1976: 76).

Eso es así, porque educar es, indudablemente, un hecho político que se reafirma con particular énfasis - como una necesidad casi imperante- en todos esos contextos sociales y colectivos que, rechazando su propio pasado autoritario, anhelan a un cambio neto y radical con regímenes de gobierno enemigos de la libertad.

La historia del constitucionalismo español corrobora esta misma idea.

Es suficiente considerar la afirmación del derecho a la educación, y de la correspondiente libertad de enseñanza, a partir de la primera Constitución española de época liberal: la Constitución de Cádiz de 1812. El Art. 366 de ese texto determinaba que "En todos los pueblos de la Monarquía se establecerán escuelas de primeras letras, en las que se enseñará a los niños a leer, escribir y contar y el catecismo de la religión católica, que comprenderá también una breve exposición de las obligaciones civiles."

Cabría recordar que esta norma vino a hacerse efectiva en un contexto social en el que, en España, la población analfabeta era largamente mayoritaria a causa de un sistema educativo público casi inexistente, en el que se implementaban metodologías que, por los mismos estándares de la época, resultaban ser arcaicas u obsoletas. Como HERNÁNDEZ PINA y otros evidencian, las razones principales que determinaron la puesta en marcha de 
un modelo de educación pública más efectivo respondían a la voluntad política de edificar un nuevo Estado de tipo liberal, fundado en el principio de voluntad democrática que entonces, como hoy- hacía necesaria la construcción de una ciudadanía formada y consciente de su nuevo papel político. Se trataba, en otras palabras, de:

\footnotetext{
"una medida más en el desmantelamiento del Antiguo Régimen y la instauración de un Estado liberal [...] y si la Nación es el argumento principal, al ciudadano se le quiere convertir en el primer actor. Este nuevo orden social precisaba de un nuevo orden educativo que le diera legitimidad y apoyo, que distinguiera a los ciudadanos, no por su nacimiento sino por la educación recibida, con un nuevo tipo de relaciones sociales, económicas y políticas" (HERNÁNDEZ PINA \& ESCARBAJAL DE HARO, 2015: 222).
}

Sin embargo, esta dimensión política del fenómeno educativo solo puede ser real y efectiva en la medida en que la educación promueva el pleno desarrollo de la personalidad.

Como sostiene SANCHES ROSSINI (2008) "educar es creer en la persona”. Eso supone reconocer y poner en valor esos rasgos de la personalidad que hacen de cualquier ser humano un unicum irrepetible, un ser dotado de dignidad. La existencia de una relación biunívoca entre dignidad humana y educación ha sido puesta de relieve por el mismo Tribunal Constitucional español en la Sentencia 236/2007, de 7 de noviembre. En esa resolución, tras matizar "la innegable trascendencia" del fenómeno educativo para el pleno y libre desarrollo de la personalidad, el supremo intérprete de la Constitución ha señalado que la mera noción de convivencia en una sociedad democrática avanzada supone la enseñanza de los valores democráticos y del respeto a los derechos humanos (LOPEZ CASTILLO, 2013: 309-332).

La enseñanza, desde luego. Pero -añadiría- también la adquisición y la íntima interiorización de esos valores morales por parte de quienes reciban esas enseñanzas.

Deberíamos recordar, a este propósito, que la misma palabra educación viene del latín educere, un verbo que expresa la capacidad de "extraer algo" o de "sacar algo hacia fuera". Se trata de ideas que se ajustan o coinciden con esa noción de educación como instrumento fundamental para el desarrollo de la personalidad, de una personalidad que no deja de ser ínsita en cada ser humano, y que frecuentemente permanece oculta por efecto de un 
conformismo social que la frustra, la reprime y le impide expresarse libera y autónomamente.

Ese reconocimiento y esa puesta en valor, según la UNESCO, pueden lograrse a través del desarrollo de diversas habilidades que, ya en 1996, la Comisión Internacional sobre la Educación para el Siglo XXI había identificado en un informe titulado "La educación encierra un tesoro" (DELORS, 1996b). Así, los sistemas educativos deberían articularse sobre cuatro pilares distintos, "cuatro aprendizajes fundamentales", es decir: "aprender a conocer", “aprender a hacer", “aprender a vivir juntos” y “aprender a ser”.

Como señala DELORS (1996a: 92), “aprender a conocer” significa "aprender a comprender el mundo que la rodea [a la persona], al menos suficientemente para vivir con dignidad, desarrollar sus capacidades profesionales y comunicarse con los demás." Lo primero que destaca en este ámbito, es que las intervenciones que postula la UNESCO se entienden dirigidas a toda la sociedad, sin diferenciaciones de tipo generacional, pues como señala GERVER (2012) "hasta el momento de exhalar nuestro último aliento estamos aprendiendo, experimentando, creciendo". Eso no impide, sin embargo, prestar particular atención a los colectivos sociales más jóvenes, para estimular en ellos la adquisición de hábitos culturales que perduren durante toda la vida. Esos hábitos, a la postre, deberían conducir al "despertar de la curiosidad intelectual" y del "sentido crítico", dos instrumentos necesarios para "descifrar la realidad [...y lograr...] al mismo tiempo una autonomía de juicio" (DELORS, 1996a: 92).

La educación como "interpretación de la realidad", de una realidad incluso conflictiva e inhumana, es la idea que también expresa NEMBRINI (2013) cuando afirma que "l'educazione è introduzione alla realtá totale [...] affermandone il senso, affermandone il significato” (p. 42). En este mismo sentido, pero desde una perspectiva jurídica, REUTER (1974: 12, citado por ALEXY, 1993: 485) considera que el derecho a la educación se caracteriza por ser un "derecho a la emancipación cultural-intelectual a la individualidad, a la autonomía, a la madurez político-social.”. 
Para ser capaces de aprender, el Informe identifica ciertas facultades específicas, cuyo ejercicio considera irrenunciable, a saber: la concentración o atención, la memoria y el pensamiento. Esas mismas facultades, indudablemente importantes, deben constituir un catálogo “de mínimos". En efecto, a ellas se podrían añadir otras virtudes igualmente necesarias, como la "curiosidad" que nos interroga, la "voluntad" que nos mueve hacia lo desconocido, y la "honestidad" que nos conduce a admitir que carecemos de ciertos conocimientos. Son todas ellas virtudes que, por otra parte, nos reenvían a las bases del pensamiento socrático, a ese "saber de no saber nada" que, desde hace dos milenios, nos enseña también otro importante valor: el de la humildad intelectual.

"Aprender a hacer" constituye, sin embargo, otro de los aspectos esenciales de la educación, según la visión de la UNESCO. En este ámbito concreto, no se trata, como en el pasado, de limitarse a la transmisión de conocimientos de tipo técnico, en un ámbito productivo concreto. En realidad, este pilar educativo debería consentir a cualquier persona la adquisición de determinadas competencias, como ser capaz de comunicar eficazmente, de trabajar en equipo, de analizar y resolver problemas, etc. Todo eso no debería ir encaminado solo y exclusivamente a impulsar y mejorar la empleabilidad de una persona en busca de trabajo. Si bien el Informe no lo ponga claramente en evidencia, "aprender a hacer" debería servir, antes que nada, para que cualquier individuo sepa y pueda realizarse como persona también en ese ámbito vital importantísimo como es el laboral. Es esta -es bueno matizarlo- una dimensión de la existencia íntimamente ligada al concepto de dignidad humana, como del resto nos recuerda la Constitución italiana de 1947 que coloca la noción de trabajo a fundamento de la República (GIUGNI, 1994: 3 y ss.).

“Aprender a vivir juntos" representa el tercer pilar descrito por el citado Informe de la UNESCO. El punto de partida que subyace a esta vertiente del fenómeno educativo arranca de una visión objetiva de la realidad que nos rodea. DELORS nos recuerda que "la historia de la humanidad ha sido siempre conflictiva" y que "los seres humanos tienden a valorar en exceso sus cualidades y las del grupo al que pertenecen y a alimentar prejuicios desfavorables hacia los demás" (1996a: 95). En esa “atmosfera competitiva”, educar supone predicar la religión de la diversidad, acercar los unos a los otros, abandonar el dogmatismo, cultivar nuevamente el espíritu crítico y, en un plano ya más pragmático, 
establecer proyectos cooperativos entre sujetos diversos, para la promover y conseguir objetivos compartidos.

En un cierto sentido, la educación debe servir también a desarrollar la capacidad de “colocarse en el lugar del otro", y así construir esa realidad descrita por CALAMANDREI (1956) cuando afirmaba que "la vita in società è fatta di solidarietà e di altruismo, che senza solidarietà e senza altruismo non vi è civiltà”, porque no deja de ser igualmente cierto que "human history becomes more and more a race between education and catastrophe” (WELLS, 1920). Estos valores también pueden y deben formar parte de la misión educativa, porque aun concediendo a los más pesimistas que los sentimientos de solidaridad y de altruismo no forman parte de la naturaleza humana, sí es de admitir que dichos valores pueden ser aclamados, exaltados y enseñados, en este último aspecto, particularmente con el ejemplo. Sin embargo, estos mismos objetivos acaban frecuentemente olvidados, como nos recuerda, entre otros, GARCIA GARCIA, pues privilegiamos:

\footnotetext{
"la competencia y el individualismo, el lucro económico y los intereses personales sobre el bien común y el interés público. Así, los procesos educativos dejan de ser interacciones comunitarias y sociales, dejan de generar aprendizajes situados y en comunidad, para pasar a ser aprendizajes individuales, que sólo tienen como objetivo aprobar el curso y certificar la capacidad para competir y dominar sobre otros o sobre un aspecto del mundo. En ningún momento pretenden cambiar, en lo íntimo de su esencia, al ser que aprende." (2018: 11 y 12).
}

Si bien el Informe no haga referencia a ello, "aprender a vivir juntos" significa también apostar por una educación que promueva la igualdad de género. En otro informe de la UNESCO, publicado más recientemente, se hace hincapié en las labores educativas como factores decisivos para la erradicación de la discriminación por razones de género:

\footnotetext{
"La educación es un factor de influencia decisivo en favor de los derechos de las mujeres. Hacer hincapié en la educación, en especial en la de las niñas, puede romper la transmisión de desventajas de una generación a otra [...]. Al mismo tiempo, si bien la medida en que la educación de los padres determina la educación de sus hijos disminuye lentamente, no deja de ser importante, lo que hace necesario intervenir para impedir que persista la desigualdad." (2020: $\mathrm{VI})$.
} 
En ese mismo documento, la UNESCO reconoce que "el sector educativo por sí solo no puede lograr la igualdad de género en la educación" (ibidem) considerado que todos los esfuerzos dirigidos a la afirmación de iguales oportunidades se miden, más ampliamente, en el terreno social, político y laboral incluso antes que en el sistema educativo. No obstante, la organización de Naciones Unidas identifica una serie de acciones fundamentales, de carácter pragmático y de factible ejecución, encaminadas a la promoción de la igualdad de género, como "asegurar una representación equilibrada de niñas y mujeres en los ámbitos de estudio de ciencia, tecnología, ingeniería y matemáticas”, "eliminar los estereotipos y los prejuicios de género de los materiales de enseñanza y aprendizaje", "lograr que las escuelas sean espacios seguros para todas las niñas y niños, libres de violencia de género", "comprometerse a impartir una educación sexual integral en todos los niveles educativos", "garantizar una representación equilibrada de mujeres en puestos de gestión y liderazgo de la educación” (Ibídem: 69-71).

El último pilar descrito por el Informe UNESCO de 1996 hace hincapié en la necesidad de que la educación sirva para "aprender a ser", una facultad que, en realidad, resume y sintetiza el contenido de las tres vertientes educativas descritas con anterioridad. Nuevamente, la Comisión enfatiza el papel de la educación como instrumento para el desarrollo de la personalidad en todas sus facetas, condición básica para la consecución de esa "libertad de pensamiento, de juicio, de sentimientos y de imaginación" que nos hace dueños y artífices de nuestros destinos (DELORS, 1996a: 97).

Sin embargo, ese "despliegue completo del hombre en toda su riqueza y en la complejidad de sus expresiones y de sus compromisos" (ibidem) solo es posible si la educación nos enseña a mirar dentro de nosotros mismos. Ese análisis introspectivo es el primer paso para la consecución de ese desarrollo global de la persona que la educación pretende. Del resto, la misma cultura helénica ponía a fundamento del concepto de $\pi \alpha l \delta \varepsilon i ́ \alpha$ el "conocimiento de

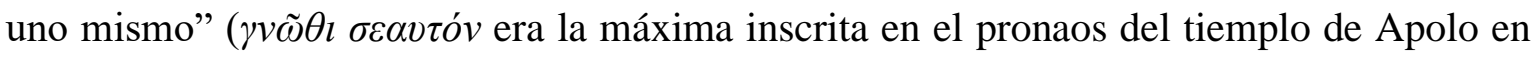
Delfos, según el relato de Pausanias). Esa facultad constituía la premisa necesaria para la consecución de una vida digna, es decir, de una vida capaz de examinarse a sí misma

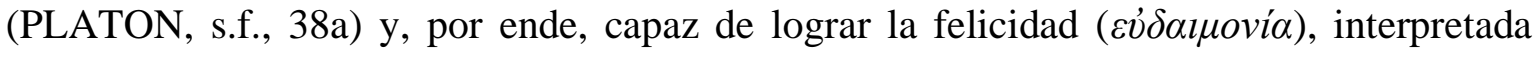
como la favorable ( $\left.\varepsilon v^{\prime}\right)$ realización de nuestro $\delta \alpha i ́ \mu \omega v$, de nuestras aspiraciones, de 
nuestras inquietudes, de nuestro talento, en definitiva, de nuestra personalidad. En este sentido, GALIMBERTI (2009: 46) recordando Demócrito, afirma que "Felicità e infelicità sono fenomeni dell'anima (eudaimonie psychès kaì kako-daimonie)', la quale prova piacere o dispiacere a esistere a seconda che si senta o non si senta realizzata. La realizzazione di sé è dunque il fattore decisivo per la felicità."

Por todo eso educar significa también impulsar y promover ese conocimiento de cada individuo de sí mismo, ese análisis introspectivo que es condición fundamental para la consecución de esos objetivos que se colocan a la base de nuestros pactos de convivencia: la búsqueda de la felicidad y la realización de la dignidad humana.

\section{La noción de educación desde la perspectiva de quién educa}

Si educar supone -como yo creo- perseguir todos los objetivos que se acaban de relatar, dedicarse a las labores educativas debería significar embarcarse en una tarea titánica.

Es evidente que la consagración de la vida profesional de un individuo a la educación supone por parte de esa misma persona la aceptación de un reto complejo y difícil y la asunción consciente de unas responsabilidades enormes.

Estas meras consideraciones deberían conducirnos a pensar que las labores educativas deberían ser, por lo menos, recompensadas proporcionalmente, tanto desde la perspectiva del reconocimiento social y colectivo, como desde un punto de vista meramente retributivo.

En realidad, los datos estadísticos que describen los niveles salariales del profesorado en los países del entorno UE nos devuelven un panorama casi opuesto al que se acaba de teorizar:

\footnotetext{
"en tres cuartas partes de los sistemas educativos, el salario bruto oficial anual mínimo de un profesor novel en todos los niveles educativos es inferior al Producto Interior Bruto (PIB) per cápita. [...] Mientras que, en algunos países, el salario máximo oficial es más del doble que el mínimo, en otros, la diferencia entre ambos es mucho menos significativa. En algunos casos, los
} 
profesores necesitan muchos años de servicio para conseguir unos aumentos relativamente bajos." (COMISION EUROPEA, 2017).

Y, sin embargo, si atendemos a estudios que analizan los factores de insatisfacción del profesorado a nivel global, encontraremos ítems como la falta de tiempo suficiente, la burocracia, la ausencia de respaldo parental, el estrés e incluso la mala actitud del alumnado en clase, pero ninguna referencia realmente relevante a las condiciones salariales del personal docente (MACBEATH, 2012: 13).

Esta circunstancia singular en una realidad social que confunde el bienestar económico con la felicidad, podría explicarse simplemente haciendo referencia al carácter esencialmente vocacional de esa profesión, en la que los niveles salariales no representan una motivación determinante para el profesorado.

Pero otra lectura de esta realidad es la que se extrae de informes que nos hablan de la docencia como de una profesión que destaca por su feminización y por unos bajos niveles salariales que no dejarían de ser otra expresión más de la llamada “brecha salarial”. Así, por ejemplo, en España según el INSTITUTO NACIONAL DE ESTADÍSTICA (2020):

"Los porcentajes de mujeres en el profesorado en el curso 2017-2018, según la enseñanza que imparten son especialmente elevados en Educación Infantil (97,7\%), en Educación Especial $(81,8 \%)$, en Educación Primaria (81,7\%) y en Enseñanza de idiomas $(74,7 \%)$ ".

Todas estas consideraciones, en realidad, apuntan a un objetivo fundamental: poner en valor la labor docente y lograr que, como conjunto social, seamos conscientes de que pocas profesiones, como la docente, inciden en nuestro bienestar colectivo en el medio y largo plazo. Eso es así, porque quién se dedique a la educación lo hace entregando su profesionalidad al "bene più prezioso di ogni società che vuole distendersi verso il futuro" (LODOLI, 2010), a un bien esencial, crítico y fundamental para nuestros modelos de convivencia: los y las jóvenes, las personas a las que, un día, tocará asumir la responsabilidad cívica y política de nuestro futuro.

Es por estas mismas razones que esta actividad profesional no puede ser encomendada con frivolidad o despreocupación a quién busque un trabajo o un empleo cualquiera. 
A tal propósito, GALIMBERTI, forzando en parte algunas conclusiones de FREUD contenidas en Zur Psychologie des Gymnasiasten (1914), afirma que "la scuola deve fare qualcosa di più che indurre i giovani al suicidio" (2014: 40 y ss.). Por eso, educar desde la perspectiva del educador debería presuponer en el docente toda una serie de capacidades (el talento, la voluntad, la perseverancia, la vocación, etc.) que deberían hacer del profesorado, un gremio de profesionales con características casi fuera de lo común. En realidad, sería suficiente no limitarse a medir, como a menudo ocurre con las pruebas públicas de acceso a la función docente, cuantitativamente una serie de conocimientos que deben formar parte del patrimonio intelectual del que aspire a enseñar. En opinión del filósofo italiano, el profesorado debería ser seleccionado también a través de otros mecanismos que sirvieran para comprobar la existencia de esas "capacidades" y de esos recursos que atañen a su capacidad de comunicación y, si cabe, de "fascinación" hacia los más jóvenes (Ibídem).

No obstante, merece la pena recordar que un docente entusiasta, comunicador, con vocación de servicio, puede igualmente ser perjudicial para su alumnado si, por ser víctima del dogmatismo, destruye la curiosidad, el espíritu crítico y la capacidad de sus alumnos de aceptar la alteridad (DELORS, 1996a: 96), cualquier alteridad que suponga el respeto de la dignidad humana.

"Amar la vida y entenderla [...] entender la vida desde la inteligencia, desde una festiva inteligencia" es para VILAS el cometido principal de cualquier docente que merezca la pena ser recordado en una novela autobiográfica (2018: 138).

Por último, no deberíamos caer en el grave error de pensar que la educación es simplemente algo que atañe a profesoras/es, enseñantes o maestras/os, desde dentro de una universidad, un instituto o una escuela.

"La educación no es una propiedad individual, sino que pertenece, por su esencia, a la comunidad". Con estas palabras JAEGER, nuevamente, nos sugiere la existencia de una unión indisoluble entre normas escritas y orales que rigen un conjunto social, y la educación que es "producto de la conciencia viva” de esas normas (2001: 3 y 4). 
NEMBRINI (2013) expresa este mismo concepto con palabras más directas, si cabe, pero igualmente ciertas:

\begin{abstract}
"l'educazione è cosa che riguarda tutti gli uomini e tutte le donne. Certo, in particolare è il mestiere dei genitori e, in altro modo, il mestiere dell'insegnante; ma è prima di tutto il mestiere dell'uomo. L'uomo per come è fatto e per la relazione che ha con altri uomini, educa: l'uomo educa sempre [...] quando ci vediamo per strada ci educhiamo, quando andiamo al lavoro ci educhiamo ed educhiamo gli altri che ci guardano. Ci vuole questo coraggio, questa lealtá per provare a guardare le cose nella loro struttura originale." (p. 36).
\end{abstract}

Se trata, en definitiva, de adquirir esta consciencia y asumir esta responsabilidad que supone no arrinconar el hecho educativo a los lugares institucionalmente prepuestos para ese fin. En eso también debería consistir nuestro papel político como miembros de una ciudadanía activa, en testimoniar con nuestros gestos, palabras y acciones, que ciertos valores constitucionales y democráticos no se enseñan solo en las escuelas o en las aulas universitarias, sino en la cotidianeidad de nuestras vidas.

\title{
5. La educación como derecho social fundamental y mínimo vital
}

En una de sus obras más conocidas, el jurista alemán ALEXY describe los "derechos sociales fundamentales" como unos derechos que facultan el individuo a reivindicar ante el Estado unas prestaciones determinadas que, de otro modo, una persona no podría conseguir, a no ser que se dieran dos presupuestos concurrentes: que en el mercado se ofrecieran esas prestaciones necesarias y que el individuo pudiera costeárselas. En el catálogo de derechos que el autor utiliza como ejemplos para explicar estas ideas, encontramos, entre otros, el derecho a la educación, definido como "derecho a prestación en sentido estricto" (ALEXY, 1993: 482) y, más adelante, como un derecho social fundamental con contenido maximalista que exige, por parte del Estado, una plena realización (Ibídem: 485).

El mismo autor precisa que la esencia de los derechos sociales $-\mathrm{y}$, por ende, del derecho a la educación- reside en la naturaleza de esas prestaciones necesarias. Dichas prestaciones, efectivamente, pueden y deben ser objeto de reivindicación en un sistema democrático pues su finalidad última consistiría en otorgar a la libertad un significado real y concreto. 
Ese mismo concepto, clave para entender el alcance fundamental de esta categoría jurídica, es el que GROS ESPIEL (1988) describe de esta manera:

"Sólo el reconocimiento integral de todos estos derechos puede asegurar la existencia real de cada uno de ellos, ya que, sin la efectividad del goce de los derechos económicos, sociales y culturales, los derechos civiles y políticos se reducen a meras categorías formales. Pero, a la inversa, sin la realidad de los derechos civiles y políticos, sin la efectividad de la libertad entendida en su más amplio sentido, los derechos económicos y sociales carecen a su vez de verdadera significación" (pp. 324 y 325).

Por todo ello, y para garantizar la efectividad de los derechos fundamentales - civiles, políticos, sociales, culturales y económicos- compete a los poderes públicos implementar iniciativas dirigidas a la remoción de las razones fácticas que impidan el ejercicio real y concreto de una libertad con contenido constitucional por parte de su titular.

Esas iniciativas, por otra parte, deberían conjugarse con otras de carácter promocional, es decir, dirigidas a la construcción de ese ámbito vital que permitiría el disfrute de esas libertades de una manera que prescindiera de los factores sociales y de mercado que caracterizan las vidas de las personas y que las personas no pueden, enteramente, dominar (ALEXY, 1993: 486 y 487).

Por esas mismas razones, por ejemplo, el mismo Tribunal Constitucional español en la Sentencia 86/1985, de 10 de julio, ha matizado que el derecho a la educación "incorpora [...] junto a su contenido primario de derecho de libertad, una dimensión prestacional, en cuya virtud los poderes públicos habrán de procurar la efectividad de tal derecho y hacerlo para los niveles básicos de enseñanza en las condiciones de obligatoriedad y gratuidad.”.

Y efectivamente, la relevancia del derecho a la educación y de su contenido nuclear consiste en eso, en su esencia de derecho de libertad que exige la ejecución de acciones positivas por parte de los poderes públicos para lograr su realización, porque solo de esa forma, como nos recuerda el Art. 9.2 CE "la libertad y la igualdad del individuo y de los grupos en que se integra" serán "reales y efectivas", y solo así será posible "facilitar la participación de todos los ciudadanos en la vida política, económica, cultural y social.”. 
Estas mismas consideraciones corroboran la elección del Constituyente español que situó el derecho a la educación en el Art. 27, es decir, en un precepto contenido en la Sección Primera del Capítulo Segundo del Título I de la CE. Ahí, como es sabido, se hallan consagrados los llamados “derechos fundamentales y libertades públicas”, es decir, ese núcleo duro de valores morales que se colocan a la base de todo el edificio político y constitucional y que, a la luz del Art. 53.2 CE, gozan del máximo nivel de protección jurídica que ese mismo Constituyente quiso y supo elaborar.

Sin embargo, la configuración jurídica del derecho a la educación en la Constitución española de 1978, descifrada a la luz de las consideraciones realizadas previamente en la primera parte de este trabajo y al comienzo de este epígrafe, pone de manifiesto las incongruencias que se sitúan a la base de una tradicional -y obsoleta (vd. entre otros, PISARELLO, 2007)- suma divisio que contrapone, jerarquizándolos, los derechos civiles y políticos a los derechos sociales, culturales y económicos.

Si para definir su naturaleza jurídica en el ordenamiento jurídico español atendieramos únicamente al criterio formal dictado por el Art. $53 \mathrm{CE}$ y siguiéramos adoptando esa interpretación fragmentada de los derechos humanos que la Constitución española reproduce, debería asombrarnos la colocación del derecho a la educación junto con los demás derechos civiles y políticos. En efecto, deberíamos asumir que, en este caso concreto -y solo en este-, el Constituyente español ha accedido a realizar una excepción ante la extraordinaria relevancia política de ese derecho social de caracter prestacional llamado derecho a la educación.

En realidad, es más correcto asumir que esa interpretación fragmentada de nuestro patrimonio de derechos fundamentales, de la que se hace eco el mismo Art. $53 \mathrm{CE}$, no es más que una proyección, en una dimensión histórica, de la contraposición existente entre diversas ideologías políticas -liberalismo vs. socialismo- (DICIOTTI, 2004: 50).

Así, es interesante evidenciar que ya en las tesis de MARSHALL -autor al que, por otra parte, algunos (vd. RUIZ MIGUEL, 1994: 651) atribuyen erróneamente el origen teórico de esa fragmentación citada con anterioridad- la defensa del derecho a la educación 
adquiere la condición de presupuesto para la realización de los derechos civiles y políticos, pues "el derecho a la libertad de palabra carece de sustancia cuando, por falta de educación, no se puede decir nada que merezca la pena o no se tienen medios para hacerse oír." (1997: 316).

Por eso mismo el sociólogo inglés, tras describir el elemento político de la organización estatal (el derecho de participación política) y su elemento social (el bienestar social), señala que "las instituciones más estrechamente conectadas con estos derechos son el sistema educativo y los servicios sociales", remarcando, de este modo, que los derechos civiles y políticos y derechos sociales tienen en la educación su auténtico trait d'union.

No obstante, definir el derecho a la educación como un derecho de libertad con contenido prestacional o, como un derecho social fundamental o más simplemente como un derecho humano esencial no agota las controversias existentes en torno a otros aspectos de su naturaleza jurídica. Sobre la mesa quedan cuestiones tan interesantes como la inclusión de ese valor moral en la noción de "derecho a un mínimo vital", asunto sobre el cual CARMONA CUENCA y JIMENA QUESADA han ofrecido interpretaciones aparentemente contrapuestas.

Así, mientras para JIMENA QUESADA la educación -junto con salud, vivienda y alimentación- constituiría el núcleo esencial del derecho a "recursos mínimos garantizados" (1997: 277), para CARMONA CUENCA la inclusión de ese derecho no estaría justificada, al considerar el derecho a un mínimo vital como la libre disponibilidad de "unos recursos económicos mínimos para hacer frente a las necesidades más perentorias del ser humano" (2006: 184).

Más allá de las dudas de carácter meramente semántico -efectivamente, es posible argumentar que no es lo mismo hablar de "mínimo vital" que de "recursos mínimos garantizados"-, tal vez, se podría zanjar la cuestión relativa a la inclusión del derecho a la educación en esa noción de mínimos contestando, con honestidad, a una serie de interrogantes: ¿estaríamos dispuestos a vivir en un modelo social en el que el acceso a la educación fuera garantizado solo para quién dispusiera de recursos económicos suficientes 
para soportar su coste?; en un modelo social como el que acabamos de describir ¿durante cuánto tiempo perdurarían esos principios constitucionales y democráticos que hemos elevado a valores fundamentales de nuestro ordenamiento jurídico?

Se trata, obviamente, de preguntas retóricas y las respuestas a las mismas deberían ser obvias. Creo firmemente que el derecho a la educación forma parte de la noción de derecho a un mínimo vital. Toda la primera parte de este trabajo ha ido en la dirección de ofrecer, en cierto modo, argumentos sólidos para defender la irrenunciabilidad de este derecho ante cualquier circunstancia y para todo conjunto social que aspire a llamarse "democrático" pues, como recuerda NINO (1996: 201) "Some goods are so fundamental to the proper working of the democratic system that if they are not provided, the democratic process will deteriorate so much that its epistemic value vanishes. " Y que esto sea así, que la educación constituya un bien irrenunciable para nuestros modelos políticos, ante cualquier circunstancia de naturaleza económica (VIDAL PRADO, 2013: 67-75) o de otra índole, lo corrobora en España la inmensa labor llevada a cabo, a lo largo de este último año, por la ciudadanía y por las autoridades públicas, todas ellas volcadas en sostener la continuidad de las actividades educativas en todos los ámbitos y en compatibilizarlas con las medidas de prevención del contagio.

\section{Conclusiones}

La cuestión relativa a los fines educativos y a la trascendencia de la educación en lo individual y en lo colectivo no es nueva, pues en realidad no ha dejado nunca de ser objeto de debate y de reflexión en cualquier comunidad preocupada de preservar esa "consciencia espiritual" de la que hablaba JAEGER. Es esta una consideración inevitable que entraña también un halo de frustración que KRIECK sintetiza eficazmente cuando afirma:

“Se debe educar al alumno para ser una personalidad armónicamente equilibrada o para darle un sentido social y de servicio? ¿Debe predominar el fin educativo de Locke o de Rousseau, de Loyola o de Franke o de Natorp? Esta discusión no cesará nunca, porque surge de las oposiciones de la realidad y de la concepción de la vida.” (1952: 8). 
En efecto, siguiendo a este autor podríamos concluir afirmando que no es posible hablar de educación, declinando este término al singular, y que debería ser más correcto tratar este mismo lema recurriendo constantemente al plural, a la idea de educaciones.

En realidad, no es ocioso recordar que tratar de la educación como de una actividad humana cualquiera, desvinculándola de sus fines y del contexto en que se desarrolla, carece de todo significado. En un modelo de convivencia democrático, orientado a la realización del principio de dignidad humana y a la puesta en valor de la condición ciudadana, educar significa transformar el ser humano en persona, es decir, en un ser consciente de esas responsabilidades que él mismo tiene hacia sí y hacía la comunidad. Un ser, además, libre de desarrollarse plenamente a través del goce y del disfrute de esos valores morales -los derechos fundamentales- que ahondan sus raíces en el concepto mismo de dignidad.

Por todo eso, en el fondo, la cuestión educativa no debería reducirse a decidir entre esas disyuntivas descritas por KRIECK -u otras parecidas-, sino en asumir que educar, en un contexto político como el nuestro, debería suponer la voluntad de mirar al ser humano como a un proyecto constantemente inacabado, que precisa de las labores educativas para florecer en esa idea de persona, de un sujeto volcado en la completa realización de sí mismo y plenamente consciente de su papel y responsabilidad ante el conjunto social.

Creo firmemente que este debería ser el cometido principal de las labores educativas en todos los ámbitos y en todos los niveles en los que se articulan. No obstante, no es posible olvidar que las sociedades actuales en las que vivimos responden a otros esquemas lógicos, en parte incompatibles con esos fines educativos descritos anteriormente.

Hace más de medio siglo HEIDEGGER (1954) nos advertía del peligro al que se exponen la cultura occidental en la llamada edad de la técnica. Cuando en nuestros conjuntos sociales los valores fundacionales propugnados en nuestros textos constitucionales ceden el paso, en la realidad concreta, a principios de naturaleza e índole distinta, como los de la eficiencia y de la productividad, no nos debe sorprender si la noción de educación es frecuentemente confundida con la de instrucción. Y, sin embargo, es necesario recordar que instruir implica simplemente la transmisión de contenidos culturales de un individuo al 
otro, mientras que educar significa preocuparse, en primer lugar, de la dimensión humana de la persona (GALIMBERTI, 2019: 39).

Así, en la edad de la técnica la instrucción se disfraza de educación. De modo que, también en este ámbito tan vital para cualquier conjunto social, se acaba imponiendo la lógica del "Denken als Rechnen" (del "pensamiento calculador") que entiende solo de utilidad, rentabilidad, eficiencia y productividad.

La misma idea de recurso humano, tan en boga en la narrativa política o económica, asume el ser humano como eso, como un recurso a emplear en los procesos productivos, un recurso que, como otros, puede ser desechado si las lógicas utilitaristas así lo exigen. Consecuentemente, en nuestros colegios proliferan contenidos -supuestamente"educativos" con los que se idolatra el bilingüismo o las nuevas tecnologías y que van encaminados, en primer lugar, a la mejora de la empleabilidad del futuro trabajador y solo en segundo lugar a la consecución de esos fines primordiales propios del fenómeno educativo. Así, también en el sector educativo, parece estar produciéndose una auténtica heterogénesis de los fines, una involución de nuestros sistemas de valores con el que culmina - por lo menos, por ahora- ese largo recorrido de la historia occidental que empezó con el reconocimiento de los primeros derechos de libertad; que siguió con la afirmación del principio de dignidad humana y que ahora, lenta e inexorablemente, degrada hacia la “cosificación” del ser humano, reducido a mero recurso productivo.

¿El sistema educativo debería ser cómplice de esta involución?

Si miramos a los principios dogmáticos consagrados en nuestras Constituciones que colocan esa dignidad a fundamento de nuestros pactos de convivencia, la respuesta debería ser jamás.

Pero merece la pena reflexionar sobre el panorama social, económico, político y cultural en que actúa el fenómeno educativo. Como se ha evidenciado a lo largo de este estudio, la educación -como, del resto, el Derecho- bebe de esos valores morales que el conjunto social practica de forma espontánea y casi inconsciente y que van evolucionando en el 
tiempo, por efecto de los distintos inputs (modelos, ideales, ejemplos, etc.) que la sociedad produce y recibe. Los valores básicos de dignidad, igualdad, pluralismo, libertad que nuestra Constitución propugna y que deberían representar un marco teleológico sólido e insoslayable, en realidad, actúan cada vez más como contrapesos, desgastándose y dejando paso a las lógicas utilitaristas en las que "el dinero es el único generador simbólico de todos los valores" (GALIMBERTI, 2009: 77).

¿Cuánto vale la dignidad? ¿Cuál es hoy la cotización de la igualdad? ¿Qué precio tiene la libertad o el pluralismo? Es imposible contestar a estas preguntas en términos aritméticos, es decir, de la única forma que el utilitarismo es capaz de entender. Así, en una sociedad ineducada, es decir, anestesiada por modelos educativos preocupados de formar sujetos que sean -antes que nada- empleables y luego dispuestos a mantener, con su trabajo y su endeudamiento a vida, el crecimiento económico, predicar que los sistemas de enseñanzas deberían promover el pleno desarrollo de la persona y de todo ese conjunto de valores constitucionales intangibles, equivale a predicar en el desierto.

Si esto es así, si los modelos educativos modernos derivan hacia las lógicas del mercado y de la economía, no debería sorprendernos si un día su logro principal acabará siendo la categoría del trabajador-consumidor, en lugar de una ciudadanía pensante. Un panorama indudablemente inquietante -es cierto- que se vuelve más inquietante todavía si consideramos que las personas felices "no consumen" (BEIGBEDER, 2001).

En 1937 FREUD afirmaba "It almost looks as if analysis were the third of those "impossible" professions in which one can be sure beforehand of achieving unsatisfying results. The other two, which have been known much longer, are education and government." (1964: 248).

Puede que esa opinión sea solo expresión del conocido pesimismo freudiano, aunque indudablemente dedicarse a la docencia en el panorama reaccionario que acabamos de describir supone, en ciertos momentos, desarrollar un fuerte sentimiento de desilusión. Y aunque admitiéramos que dedicarse a la educación significa eso, consagrarse a una "profesión imposible", ni la frustración ni esa supuesta imposibilidad deberían ser razones 
suficientes para perder de vista el contexto de fondo que describe la educación como una de las actividades humanas más necesarias y uno de los derechos humanos más esenciales.

Las razones a la base de ello han ocupado las páginas centrales de este trabajo en las que he procurado describir la labor educativa como ese proceso de transmisión de valores morales, llevado a cabo en un sentido crítico y, por ende, dirigido a examinarlos, renovarlos o sustituirlos en los cimientos de nuestros pactos de convivencia.

Como hemos visto, este proceso, en su esencia más auténtica, llama a la participación de la comunidad entera. La circunstancia por la que algunos han asumido la responsabilidad de dedicar su vida profesional a las labores educativas no exime al resto de la colectividad de aceptar que la educación es también tarea de todos.

Eso es así porque educar significa enseñar a interesarse por la realidad común y, por lo tanto, a actuar como un sujeto político activo, consciente e informado. Algo que no se resuelve exclusivamente en el depósito de una papeleta electoral en una urna, una vez cada cuatro años.

Como he matizado a lo largo de este artículo, educar implica también el desarrollo de nuestra condición humana a través de instrumentos formidables que nada tienen de tecnológico: como la literatura que es, como dijo MO YAN "un espejo para mostrar los sentimientos humanos" (TORRES SEOANE, 2019). De este modo, la literatura, como otras formas de arte, nos da acceso al mundo del sentir humano, sentimos lo que otros sintieron antes que nosotros y aprendemos valores como la solidaridad, la compasión, la piedad y esa empatía que supone la capacidad de ponerse en el lugar de otra persona. ${ }^{2}$

La educación nos llama a interrogar nuestras esencias y, a través de ello, nos permite desarrollar ese patrimonio de habilidades y capacidades que hemos adquiridos al principio y a lo largo de nuestras vidas. De este modo, la educación nos permite conocer y

\footnotetext{
${ }^{2}$ Lo que, en italiano, traducimos con la palabra immedesimazione que, literalmente, supone una íntima participación en los sentimientos o en la visión del mundo de otra persona, sin por ello llegar a identificarse plenamente en ella.
} 
desarrollar nuestro $\delta \alpha i \mu \omega v$, ese talento innato que es clave para la consecución de la felicidad.

La educación, en definitiva, nos permite ser personas, gozar plenamente de nuestras libertades y de nuestros derechos, asumiendo nuestros deberes hacia nosotros mismos y hacia la sociedad. Y si todo eso, para algunos, supone un precio excesivo, es preciso saber que para nuestras sociedades más cara resultaría la ignorancia (LANDERS, 1975).

\section{Referencias bibliográficas}

ALEXY, R. (1993). Teoría de los derechos fundamentales. (E. Garzón Valdés, Trad.) Madrid: Centro de Estudios Políticos y Constitucionales.

ARISTÓTELES. (s.f.). Política.

BARRENA SANCHEZ, J. (octubre - diciembre de 1971). Los fines de la educación en J. Ortega y Gasset. Revista Española de Pedagogía, 29(116), 393-416.

BEIGBEDER, F. (2001). Lire 26.900. (A. Ferrero, Trad.) Milano: Feltrinelli.

CALAMANDREI, P. (1956). Arringa del 30 marzo 1956 presso il Tribunale Penale di Palermo. Quaderni di Nuova Repubblica(4).

CARMONA CUENCA, E. (2006). Los derechos sociales de prestación y el derecho a un mínimo vital. Nuevas Políticas Públicas. Anuario multidisciplinar para la modernización de las Administraciones Públicas(2).

COMISION EUROPEA. (2017). Salarios y complementos del profesorado y de los directores de centros educativos en Europa 2015/2016. Eurydice - Datos y cifras.

DELORS, J. (1996a). Los cuatro pilares de la educación. El Correo de la UNESCO. Una Educación para el siglo XXI: aprender a aprender. 
DELORS, J. (1996b). La Educación encierra un tesoro, informe a la UNESCO de la Comisión Internacional sobre la Educación para el Siglo XXI (compendio), ED.96/WS/9. París: UNESCO. Recuperado el 28 de febrero de 2020, de https://unesdoc.unesco.org/ark:/48223/pf0000109590_spa

DICIOTTI, E. (2004). Stato di Diritto e Diritti Sociali. Diritto e Questioni Pubbliche(4).

FREIRE, P. (1976). La educación como practica de la libertad. (L. Ronzoni, Trad.) Madrid: Siglo XXI Ed.

FREUD, S. (1914). Zur Psychologie des Gymnasiasten. Viena.

FREUD, S. (1964). The Standard Edition of the Complete Psychological Works of Sigmund Freud Volume XXIII (1937-39): Moses and Monotheism, An Outline of Psychoanalysis, and Other Works. (J. Strachey, Trad.) Londres: Hogarth Press.

FREUD, S. (1977). Opere di S. Freud. Torino: Bollati Boringhieri.

GALIMBERTI, U. (2009). I miti del nostro tempo. Milano: Serie Bianca Feltrinelli.

GALIMBERTI, U. (2014). Giovane hai paura? Venezia: Marcianum Press.

GALIMBERTI, U. (2019). El huésped inquietante: El nihilismo y los jóvenes. Barcelona: Plataforma Actual.

GARCÍA GARCÍA, J. J. (2018). Educar para qué. Revista UNIPLURIVERSIDAD, 18(1).

GERVER, R. (2012). Crear hoy la escuela de mañana: la educación y el futuro de nuestros hijos. (T. T. Mora, Trad.) Madrid: Ediciones SM.

GIUGNI, G. (1994). Fondata sul lavoro? Bologna: Ediesse.

GROS ESPIEL, H. (1988). Estudios sobre derechos humanos. Madrid: Civitas.

HERNÁNDEZ PINA, F.; ESCARBAJAL DE HARO, A. \& MONROY HERNÁNDEZ, F. (julio - diciembre de 2015). Deudores de Cádiz: la Constitución de 1812 y la educación. Revista Historia de la Educación Latinoamericana, 17(25) 
INSTITUTO NACIONAL DE ESTADÍSTICA. (2020). Mujeres y hombres en España. Madrid: INE. Recuperado el 3 de marzo de 2021, de https://www.ine.es/ss/Satellite?L=es_ES\&c=INESeccion_C\&cid=1259925481851\&p=125 4735110672\&pagename=ProductosYServicios\%2FPYSLayout\&param1=PYSDetalle\&par $\underline{\operatorname{am} 3=1259924822888}$

JAEGER, W. W. (2001). Paideia: los ideales de la cultura griega. (Vol. I). (J. Xiral, Trad.) México DF: Fondo de Cultura Económica México.

JIMENA QUESADA, L. (1997). La Europa social y democrática de Derecho. Madrid: Dykinson.

KELSEN, H. (1934). Reine Rechtslehre. Leipzig y Wien: Deutlicke.

KELSEN, H. (1979). Allgemeine Theorie der Normen. Wien: Manz-Verlang.

KRIECK, E. (1952). Bosquejo de la ciencia de la educación. Buenos Aires: Losada.

LANDERS, A. (4 de octubre de 1975). Things you always wanted to know about belly buttons. The Dispatch, 4.

LODOLI, M. (4 de octubre de 2010). Il silenzio dei miei studenti che non sanno più ragionare. Repubblica.

LOPEZ CASTILLO, A. (2013). Formación de la identidad personal y educación: apuntes. Anuario de la Facultad de Derecho de la Universidad Autónoma de Madrid(17).

MACBEATH, J. (2012). Future of Teaching Profession. Cambridge, UK: University of Cambridge, Leadership for learning.

MARIN, K. (28 de mayo de 1978). Entrevista. Paulo Freire: 'La educación es siempre un quehacer político'. El Pais, https://elpais.com/diario/1978/05/20/sociedad/264463223_850215.html Recuperado el 28 de febrero de 2020. 
MARSHALL, T. H. (1997). Ciudadanía y clase social. (T. M. Casado y F. J. Noya Miranda, Trad.) Revista Española de Investigaciones Sociológicas, 79.

MARTÍN ARMENGOL, R. A. (enero - junio de 2013). La validez del derecho como deber de obediencia. Politeia, 36(50).

MILIONE, C. (enero - abril de 2020). La noción de seguridad en la doctrina del Tribunal Europeo de Derechos Humanos: referencias al derecho a la tutela judicial efectiva. Revista de Derecho Político(107).

NEMBRINI, F. (2013). Di padre in figlio. Conversazioni sul rischio di educare. Milano: Ares.

NINO, C. S. (1996). The Constitution of Deliberative Democracy. New Haven, RI: Yale University Press.

OBAMA, B. (2020). A promise land. New York, NY: Crown.

PISARELLO, G. (2007). Los Derechos Sociales y sus garantías: elementos para una reconstrucción. Madrid: Trotta.

PLATÓN. (s.f.). Apología de Sócrates.

REAL ACADEMIA ESPAÑOLA. (2020). Diccionario de la Lengua Española. Recuperado el 27 de febrero de 2020, de lema "Educar": https://dle.rae.es/?w=educar

REUTER, L. R. (1974). Soziales Grundrecht auf Bildung? DVBl.

RUIZ MIGUEL, A. (1994). Derechos liberales y derechos sociales. DOXA: Cuadernos de Filosofía del Derecho(15-16).

SANCHES ROSSINI, M. A. (2008). Educar es creer en la persona. Madrid: Narcea S.A. de Ediciones.

TOMAS Y VALIENTE, F. (1981). Voto particular a la Sentencia del Tribunal Constitucional, 5/1981, de 13 de febrero. 
TORRES SEOANE, J. (30 de Julio de 2019). Mo Yan: "La literatura es un espejo para mostrar los sentimientos humanos". Lamula.pe, https://elarriero.lamula.pe/2019/07/30/moyan-la-literatura-es-un-espejo-para-mostrar-los-sentimientos-humanos/javierto/

Recuperado el 17 de marzo de 2021.

UNESCO. (2020). Informe de seguimiento de la educación en el mundo 2020: informe sobre género, Una nueva generación: 25 años de esfuerzos en favor de la igualdad de género en la educación. París: UNESCO. Recuperado el 3 de marzo de 2021, de https://unesdoc.unesco.org/ark:/48223/pf0000375470

VIDAL PRADO, C. (2013). El derecho a la educación en tiempos de austeridad. Nuevas Políticas Públicas. Anuario multidisciplinar para la modernización de las Administraciones Públicas(8).

VILAS, M. (2018). Ordesa. Madrid: Alfaguara.

WELLS, H. G. (1920). The Outline of History. London: George Newnes. 